\title{
Educação física e inclusão: a experiência na Escola Azul
}

\author{
José Francisco Chicon* \\ Katiuscia Aparecida Moreira de Oliveira Mendes ${ }^{* *}$ \\ Maria das Graças Carvalho Silva de $\operatorname{Sá}^{* * *}$
}

\begin{abstract}
Resumo: Estudo de caso com aproximações etnográficas, objetivando investigar e analisar o processo de inclusão de dois alunos com necessidades educacionais especiais (NEEs) no espaço-tempo das aulas de Educação Física. Os instrumentos utilizados foram o diário de campo e a observação participante. Os dados empíricos nos chamam a atenção para um problema grave na Educação/Educação Física: a escola, no processo de inclusão, pode estar formando os alunos para reproduzirem atitudes de segregação de alunos com NEEs por deficiência, tornando natural a não participação deles nas atividades escolares e sociais, mantendo, por dentro do processo de inclusão, a exclusão.
\end{abstract}

Palavras chave: Inclusão. Educação Física Escolar. Cotidiano.

Este estudo ${ }^{1}$ resulta de uma pesquisa realizada originalmente como dissertação de mestrado em uma Escola de Ensino Fundamental no Município de Vitória-ES, consistindo no acompanhamento educacional de dois alunos, um com baixa visão, de 11 anos, e o outro com síndrome de Down, de 14 anos, inseridos em uma turma regular do $6^{\circ}$ ano. As observações foram realizadas

'Professor adjunto do Departamento de Ginástica da Universidade Federal do Espírito Santo, Vitória, ES, Brasil. E-mail: chiconjf@yahoo.com.br

"Professora de Educação Física. E-mail: katiuscia.mendes@hotmail.com

"*Professora adjunta do Departamento de Ginástica; da Universidade Federal do Espírito Santo - E-mail: mgracasilvasa@gmail.com

${ }^{1}$ Estudo financiado pela CAPES. 
três vezes por semana, durante o período de março a julho de 2009, perfazendo um total de 112 horas. Deixamos os demais dias para sistematização do caderno de campo e atividades de estudo. O tempo de observação em cada dia foi de 4 horas e 20 minutos, em um total de 26 dias. Os dois alunos sujeitos do estudo eram observados nos diferentes espaços-tempos da escola (na sala de aula regular, na aula de Educação Física, no recreio...), desde a hora em que chegavam até o momento em que deixavam a escola. No entanto, para efeito deste artigo nos ateremos a descrever e analisar o espaçotempo das aulas de Educação Física.

Devido à natureza da questão, optamos pelo desenvolvimento de uma pesquisa na perspectiva histórico-cultural, com uma abordagem qualitativa. Quanto à metodologia utilizada no trabalho de campo, a opção foi realizar um estudo de caso de inspiração etnográfica, no intuito de compreender a fundo os movimentos, no contexto dessa escola para promover a inclusão. Os dados foram coletados e registrados em diário de campo e a observação foi participante. Além disso, durante o processo de coleta de dados, fizemos uso de conversas informais com os sujeitos do estudo e com outros participantes, com o objetivo de obter informações em processo sobre o cotidiano dos alunos com deficiência na escola. Os dados foram analisados pela técnica de análise de conteúdo (BARDIN, 1994), tendo a divulgação sido autorizada pelo Termo de Consentimento Livre e Esclarecido.

O estudo objetiva investigar e analisar o processo de inclusão de dois alunos com NEEs (aluno com baixa visão e aluno com síndrome de Down) no espaço-tempo das aulas de Educação Física.

A questão que norteou nossas preocupações foi assim configurada: como ocorre o processo de inclusão de alunos com NEEs no espaço-tempo das aulas de Educação Física? 
Acreditamos que a questão da inclusão escolar de alunos com necessidades educacionais especiais (NEEs) ${ }^{3}$ constitui um tema de suma importância para a construção de uma escola democrática e de inclusão social. Dessa forma, é bom evidenciar o eixo de reflexão que orientou nossa análise para a escrita deste artigo - inclusão e exclusão: tensões, desafios e possibilidades na Educação Física.

Julgamos que a Educação Física pode contribuir para que os alunos tenham experiências para além de seu cotidiano, que essa disciplina pode ser uma auxiliar no processo de inclusão, mas tem também um poder inverso, pode ajudar a manter o status quo.

As raízes de legitimação da Educação Física, ou melhor, "[...] a educação do corpo nas escolas" (BRACHT, 2009, p. 18) têm um histórico de exclusão não somente da pessoa com deficiência, mas também do gordo, do lento, do pouco habilidoso, das meninas, entre outros. Daí o questionamento: estaria esse passado de segregação contribuindo para as dificuldades de inclusão nas aulas de Educação Física nos dias atuais?

\section{INCLUSÃO/EXCLUSÃO DE ALUNOS COM NECESSIDADES EDUCACIONAIS ESPECIAIS NAS AULAS dE EdUCAÇÃo FísICA}

Considerando a escassez de estudos específicos na área de Educação Física escolar e a inclusão de alunos com NEEs ${ }^{4}$, permitimo-nos aqui trazer as contribuições do estudo de Rodrigues (2000), com o intuito de apenas mencionar importantes destaques dessas produções.

\footnotetext{
${ }^{3}$ De acordo com a resolução n. 2/2001, em seu art. 5ํㅡ, consideram-se educandos com necessidades educacionais especiais os que, durante o processo educacional, apresentarem: "I- dificuldades acentuadas de aprendizagem ou limitações no processo de desenvolvimento que dificultem o acompanhamento das atividades curriculares, compreendidas em dois grupos: a) aquelas não vinculadas a uma causa orgânica específica; b) aquelas relacionadas a condições, disfunções, limitações ou deficiências; II- dificuldades de comunicação e sinalização diferenciadas dos demais alunos, demandando a utilização de linguagens e códigos aplicáveis; III- altas habilidades/superdotação, grande facilidade de aprendizagem que os leve a dominar rapidamente conceitos, procedimentos e atitudes".

${ }^{4}$ Consulta ao banco de teses e dissertações da Capes, acesso em 14 de dezembro de 2009.
}

Vovimento, Porto Alegre, v. 17, n. 04, p. 185-202, out/dez de 2011. 
Os estudos de Rodrigues (2000), apesar de tratarem da realidade de Portugal, indicam-nos que a Educação Física, como um componente curricular, pode contribuir ou ser um empecilho para que a escola seja ou se torne mais inclusiva. Para esse autor, existem características a favor da Educação Física inclusiva: os conteúdos ministrados nessa disciplina são flexíveis e seus professores geralmente desenvolvem atitudes positivas e dinâmicas ao permitirem participações de alunos que evidenciam dificuldades.

Porém o autor afirma que o tema da educação inclusiva em Educação Física tem sido insuficientemente tratado e, quando abordado, é percebido de forma deturpada, como se houvesse uma dimensão de aparências e uma dimensão de constatações.

\subsection{As APARÊNCIAS}

Existem várias razões pelas quais a Educação Física tem possibilidades de ser um adjuvante para a construção da educação inclusiva.

a) Em primeiro lugar, em Educação Física os conteúdos ministrados apresentam um grau de determinação e rigidez menor do que outras disciplinas [...]. Assim, aparentemente a Educação Física seria uma área curricular mais facilmente inclusiva devido à flexibilidade inerente aos seus conteúdos o que conduziria a uma maior facilidade de diferenciação curricular.

b) Em segundo lugar, os professores de Educação Física são vistos como profissionais que desenvolvem atitudes mais positivas face aos alunos que os restantes professores. Talvez devido aos aspectos fortemente expressivos da disciplina, os professores são conotados como profissionais com atitudes mais favoráveis à inclusão e que consequientemente levantam menos problemas e encontram soluções mais facilmente para casos difíceis.

c) Em terceiro lugar a Educação Física é julgada uma área importante de inclusão dado que permite uma ampla participação mesmo de alunos que evidenciam dificuldades [...]. Ainda que conscientes das diferentes aptidões específicas de cada um, entende- 
se que a Educação Física é capaz de suscitar uma participação e um grau de satisfação elevado de alunos com níveis de desempenho muito diferentes (RODRIGUES, 2000, p. 5-6).

\subsection{As CONSTATAÇÕES}

Rodrigues (2000) pensa que as constatações sobre a efetiva contribuição da Educação Física para a inclusão de alunos com dificuldades são mais preocupantes. Em relação às atitudes mais ou menos positivas dos professores de Educação Física em face à inclusão de alunos com dificuldades, Rodrigues (2000) afirma que não encontrou a homogeneidade presente nas aparências, verificando que as atitudes mais ou menos positivas não podem ser relacionadas com a disciplina Educação Física, mas sim com diversos tipos de variáveis que é necessário levar em conta.

O autor supracitado anuncia que os estudos feitos sobre essa temática indicam importantes diferenças nessas atitudes que dependem de vários fatores, entre os quais realçou os seguintes: o gênero do professor (as mulheres expressaram atitudes mais positivas que os homens); a experiência anterior (os professores com mais experiência demonstraram atitudes mais positivas); o conhecimento da deficiência do aluno (os professores que conheciam melhor a deficiência evidenciavam atitudes mais positivas).

Nesse bojo, Rodrigues (2000) menciona que os aspectos da formação dos professores de Educação Física em Necessidades Educacionais Especiais deixam, em Portugal, muito a desejar. Chicon (2005, p. 53) afirma que o mesmo se aplica ao Brasil e esclarece o motivo:

No Brasil, somente a partir do Parecer $n^{\circ} 215$, de 11 de março de 1987, do Conselho Federal de Educação, a disciplina Educação Física Adaptada foi elencada, dentre outras, como sugestão para compor os novos currículos dos Cursos de Graduação em Educação Física, que deveriam começar a funcionar no início da década de 1990. Ela prevê a atuação do professor de Educação Física com as pessoas que apresentam NEEs. Em nosso entendimento, essa é uma das 
razões pelas quais muitos professores de Educação Física, hoje atuantes nas escolas, não receberam em sua formação conteúdos e/ou assuntos pertinentes à Educação Física adaptada ou à inclusão.

Nesse sentido, acreditamos que a Educação Física pode promover a humanização das relações sociais, mas, para isso, o professor deve ter o cuidado para que todos se beneficiem do processo ensino-aprendizagem, independentemente de serem meninos ou meninas, de terem deficiência ou não.

Na sequência, apresentaremos a análise e discussão do processo de in/exclusão no espaço-tempo da Educação Física da Escola Azul, a partir da perspectiva de Murilo (aluno com baixa visão) e de Leonel (aluno com síndrome de Down) ${ }^{5}$.

\section{A EDUCAÇÃo FísICA E A INCLUSÃo NA ESCOLA AZUL: O QUE DIZEM MURILO E LEONEL SOBRE A EDUCAÇÃO FíSICA}

As aulas de Educação Física na Escola Azul, em linhas gerais, podem ser descritas da seguinte forma: ocorriam três vezes por semana, com duração de 50 minutos. Conforme um acordo feito entre professora e alunos no início do ano, uma das aulas na semana era aberta à escolha dos alunos quanto ao tipo de atividade que gostariam de realizar. O futebol para os meninos e voleibol para as meninas foi a opção predominante.

Para o início de cada aula, os alunos dirigiam-se à quadra ao encontro da professora. O conteúdo desenvolvido no período observado era mesclado entre diferentes esportes (atletismo, futebol, voleibol, handebol), que eram apresentados aos alunos de forma assistemática, ora promovendo uma vivência prática do voleibol, ora do futebol, do atletismo, retornando ao voleibol, sem que houvesse uma preocupação com a sistematização e progressão na transmissão do conhecimento relativo a uma dessas modalidades esportivas. A

${ }^{5}$ Os nomes dos participantes do estudo citados no texto são fictícios.

Movimento, Porto Alegre, v. 17, n. 04, p. 185-202, out/dez de 2011. 
rotina era a vivência prática do jogo em si, das modalidades esportivas citadas. Era comum observar alguns alunos não participando das aulas, dentre eles, Leonel e Murilo.

Especificamente no caso de Leonel e Murilo, a professora disponibilizava uma bola de basquetebol para eles e os orientava a realizar arremessos na cesta localizada ao lado da quadra. Leonel se mantinha nessa atividade durante o maior tempo da aula. Murilo pouco se envolvia, às vezes procurava se juntar ao grupo de meninas que brincavam de voleibol fora da quadra ou se dirigia à sala de atendimento educacional especializado. Percebemos aqui a falta de importância dada à Educação Física por Murilo e pela própria professora, como se esse componente curricular não fosse relevante para a formação educacional do aluno.

Nossa hipótese é que, devido ao tipo de deficiência, Leonel não conseguia estabelecer uma postura crítica em relação à situação imposta, mas o gosto pela bola de basquete (modalidade por ele praticada na APAE) trazia-lhe grande satisfação pessoal, se compararmos com outras atividades da escola. Entretanto, esse era também um espaço sem cobranças de resultados. Por outro lado, Murilo percebia a falta de sentido/significado em manter-se durante 50 minutos, muitas vezes sozinho, executando algo que não o beneficiava e nem mesmo trazia divertimento.

Nessa organização, não havia interação de Leonel com os outros colegas da turma, nem mesmo de Leonel com Murilo. No caso de Murilo, por sua iniciativa de se juntar, às vezes, ao grupo de meninas, ocorria certo entrosamento. Com base em Vygotsky (1991), acreditamos que tal ausência de relacionamentos sociais nas aulas prejudica o aprendizado da criança, pois a interação entre os sujeitos é fundamental para o desenvolvimento pessoal e social, pois pode transformar a realidade de cada sujeito, mediante um sistema de trocas.

No caso dos alunos que não apresentam deficiência, mesmo com a ausência de sistematização dos conteúdos, eles tinham a possibilidade de aprender entre si pelas trocas de experiências 
(observamos, em algumas aulas, alunos que ensinavam aos colegas passos de dança e gestos esportivos); já no caso dos alunos com deficiência, uma barreira atitudinal da professora impedia essa possibilidade.

A aula de Educação Física era um espaço de não valorização das relações sociais para Leonel. Ocorria o mesmo em sala de aula, no recreio e em diversos espaços e tempos da escola. Podemos constatar esse fato observando a seguinte cena:

"Leonel encontrava-se arremessando a bola de basquete. Um colega começa a brincar com ele e a professora interrompe dizendo: 'Essa bola é só dele', e ele prossegue brincando sozinho" (CADERNO DE CAMPO, 2009, p. 14). Perguntamos: em frente a essa situação: como os colegas podem reconhecer e valorizar Leonel como amigo?

Com Murilo, situação parecida pode ser destacada: Murilo recebe uma bola de basquete para ficar arremessando sozinho enquanto os demais participam da aula. A fala da professora é: "Aqui está sua bola, Murilo, pra você não se machucar" (CADERNO DE CAMPO, 2009, p. 17). A professora, ao segregá-lo e protegê-lo, deixa de encorajá-lo a integrar o grupo e de incentivar o grupo a percebê-lo, a ajudá-lo e a respeitá-lo, pois, segundo Carvalho (2006, p. 58),

[...] as barreiras a aprendizagem (temporárias ou permanentes) fazem parte do cotidiano escolar dos alunos e se manifestam em qualquer etapa do fluxo de escolarização. Barreiras existem para todos, mas alguns requerem ajuda e apoio para seu enfretamento e superação.

As chamadas barreiras atitudinais são um grande empecilho, entre outros, para a concretização do projeto de inclusão educacional (CARVALHO, 2006). Situações em que professores têm atitudes desfavoráveis revelam a falta de conscientização/preparo da sociedade de forma geral. Carvalho (2006, p. 58), lembra ainda que:

[...] as dificuldades se transformam em problemas na medida em que não sabemos, não queremos ou não dispomos de meios para enfrentá-las. Neste 
caso formam-se as barreiras, os entraves, alguns se tornando crônicos e de mais difícil superação. Penso que - na sociedade em geral, e nas comunidades escolares, em particular - as mais significativas são as barreiras atitudinais.

Percebemos que as aulas de Educação Física vivenciadas por Leonel, mesmo sem a interação dos colegas, apenas dele com ele mesmo, não ocorriam dessa forma por uma opção dele, que não se colocava em um quadro de autoexclusão, mas sim pelas condições colocadas pela conduta da professora de afastá-lo do grupo e do espaço da aula.

A Educação Física era a aula preferida de Leonel. Ele sempre a aguardava ansiosamente, mas nunca iniciava a aula junto com a turma. Normalmente ele esperava a professora dar as coordenadas para os outros alunos e depois pegar uma bola de basquete para ele. Sempre que chegávamos à escola, Leonel nos abordava para cumprimentos. Perguntávamos: "Hoje tem aula de quê?". Ele respondia: "Educação Física!", mesmo que não fosse dia dessa aula. Estávamos instigados a saber: o que essa aula oferecia a mais? $\mathrm{O}$ que a diferenciava das demais?

Essa situação nos levou a refletir sobre se realmente era a aula de Educação Física a preferida de Leonel ou se era, na verdade, esse espaço-tempo chamado de Educação Física em que ele vivencia a possibilidade de liberdade, de obter um objeto para diversão e satisfação pessoal: a bola. Ele realizava a atividade pelo simples prazer de repetir o gesto, como em um jogo de exercício ${ }^{6}$, uma vez que não interagia com os colegas e nem recebia orientação didáticopedagógica da professora. Observando esse aluno nos espaços de sala de aula, vimos que esses momentos de brincar/divertir não se evidenciavam. Talvez isso fosse um fator diferencial para Leonel mencionar esse gostar do que seria para ele a aula de Educação Física.

\footnotetext{
${ }^{6}$ Os jogos de exercício abrangem a repetição de sequências já determinadas de ações e manipulações por mero prazer vindo da habilidade de atividades motoras. Sua finalidade é o próprio prazer funcional (DAVIS; OLIVEIRA, 2003).
} 
Trazendo Leontiev (1991, p. 59) para esse diálogo, sobre essa situação vivenciada por Leonel nas aulas de Educação Física e nos outros espaços-tempos da escola, ele indagaria nos levando a refletir: "Estas crianças [com deficiência] têm de ser verdadeiramente postas à margem, ou o seu destino está determinado pela ação de condições e circunstâncias, condições que poderiam ser mudadas, circunstâncias que poderiam ser eliminadas para lhes permitir um desenvolvimento?".

Em relação a Murilo, quando indagamos pela primeira vez, informalmente, sobre o gosto pelas aulas de Educação Física, ele respondeu: "Não gosto de futebol, sempre erro, porque não vejo a bola de longe. A bola machuca que é pesada, a de vôlei é leve e basquete eu consigo jogar sozinho".

Murilo dizia gostar das aulas de Educação Física, mas sempre pedia para ir ao laboratório pedagógico durante essa aula e beneficiava-se pouco das práticas de Educação Física. Em outras disciplinas curriculares, Murilo apresentava bom desempenho acadêmico, graças às estratégias pedagógicas implementadas pela escola para atender às suas peculiaridades, tais como: ampliação de materiais didáticos, posicionamento do aluno à frente na sala de aula, planejamento conjunto entre o professor especialista e os professores das disciplinas, entre outras. No caso específico da Educação Física, o planejamento em conjunto com a professora especialista não ocorria, provavelmente, em razão de a professora não demonstrar dificuldade no trato didático-pedagógico com os alunos com deficiência.

Trata-se de uma forma de dispensa oculta, já que formalmente os dois alunos com deficiência estavam "participando" da aula, pois eles não recebiam falta no diário de classe e não foram reprovados na disciplina, apesar das muitas ausências. Entendemos que a Educação Física é um direito; não é uma opção descartável. Como é um direito, nenhum aluno pode ser dispensado.

Rodrigues (2000, p. 9) caracteriza o episódio de "dispensa" das aulas como uma prática segregacionista em Educação Física: 
A 'dispensa' das aulas é bem a expressão da dificuldade real que os professores de Educação Física têm de criar alternativas positivas e motivadoras para alunos com dificuldades. A dispensa surge, por regra, sem que o professor seja consultado, sem que sejam estudadas outras hipóteses e [...] freqüentemente com algum alívio do professor que se sente pouco capaz face aos seus recursos e à informação e formação que dispõe de dar resposta ao caso. Caberia aqui lembrar que quando um aluno tem dificuldades, por exemplo, em Língua Portuguesa a solução passa freqüentemente por intensificar as suas oportunidades de aprendizagem e por muitas dificuldades que [o aluno] evidencie não pode ser dispensado desta disciplina; pode, no entanto, se evidenciar dificuldades em Educação Física, ser dispensado. Isto é, sem dúvida, menosprezo pela Educação Física.

Parece que todos percebiam a falta de proposta na aula e até naturalizavam esse fato, porém nada foi feito para modificar esse quadro. Esse "não fazer nada", a partir da discussão feita por Duarte (2007), pode ser apontado como um elemento essencial para a não concretização do movimento de educação inclusiva, já que a escola, numa perspectiva sócio-histórica, é mediadora entre o conhecimento cultural produzido e os alunos.

Mas temos que ter claro, como nos adverte Chicon (2005, p. 51), que:

Incluir na Educação Física não é simplesmente adaptar essa disciplina escolar para que uma pessoa com NEEs possa participar da aula, mas é adotar uma perspectiva educacional cujos objetivos, conteúdos e métodos valorizem a diversidade humana e que esteja comprometida com a construção de uma sociedade inclusiva.

Em face aos dados empíricos descritos que nos fornecem elementos significativos sobre a dinâmica das aulas de Educação Física, ensaiamos algumas contribuições para o campo, já que as discussões sobre Educação Física inclusiva ainda são incipientes, e 
são necessárias algumas sugestões de reversão das atuais práticas, nas quais os alunos com NEEs estão incluídos no ambiente regular de escolarização, porém sem acesso ao currículo escolar.

Para tanto, dialogamos com Mittler (2003), quando aponta uma estratégia que consideramos interessante para a área. Trata-se do arranjo de situações que possibilitem a ajuda ao outro como possível experiência positiva a ser valorizada. Estamos falando da aprendizagem colaborativa entre alunos ou crianças apoiando crianças.

Em geral, ajuda e apoio são determinados casualmente e sem planejamento ou intervenção dos professores, embora, em países com classes com um grande número de estudantes, os professores assegurem que as crianças com habilidades variadas se sentem próximas, de forma que aquelas mais capazes possam ajudar seus colegas vizinhos que podem estar lutando para entender o que é esperado deles.

Porém, os professores devem assegurar que todos os alunos sejam beneficiados e que o grupo não seja forçado a trabalhar no ritmo dos estudantes mais lentos ou daqueles mais rápidos. Ainclusão bem-sucedida e a participação de alunos nas aulas e na vida da escola depende significativamente das outras crianças e, com certeza, da mediação do professor. O que precisa ficar claro, segundo Mitller (2003), é que, ainda que muitos outros recursos possam faltar, em todas as classes não há falta de estudantes.

\section{Considerações Finals}

A inclusão é determinada por lei, os alunos estão na escola, mas a inclusão precisa agora ser garantida principalmente pelos profissionais da educação e pela sociedade. Trazemos aqui algumas palavras muito bem colocadas por Nóvoa a esse respeito (prefaciando CHICON; DRAGO; VICTOR, 2010): 
Conseguimos que todos estivessem na escola, mas ainda não conseguimos que todos aprendessem na escola [...].

É preciso que nos centremos (concentremos) nas tarefas da aprendizagem. É preciso que todos os alunos aprendam verdadeiramente. É preciso que eles adquiram, no decurso da escolaridade, os instrumentos básicos para a integração na sociedade do conhecimento.

Por isso, quero deixar três alertas que são, na verdade, três provocações. A escola deve atender aos problemas sociais? Sim. A escola deve favorecer as dimensões lúdicas? Sim. A escola deve promover as identidades culturais e os laços afectivos? Sim. Mas estes três gestos são meios para que a escola cumpra a sua missão. E quando os meios são transformados em fins a escola perde a razão de ser.

Pensamos que o aluno com NEEs não vai para a escola para um dia ser incluído; ele vai porque tem o direito de estar na escola, direito que é garantido a todo cidadão. Não estamos dizendo que é fácil fazê-lo. Continuamos a afirmar que o processo é dificultoso para o sistema educativo, mas também para o aluno "incluído".

No que diz respeito à socialização dos alunos com deficiência no grupo, dois episódios revelam bem essa relação: o dia em que a professora de Educação Física se encontrava envolvida com o movimento de greve e, por isso, apenas distribuiu bolas no horário da aula e não ministrou a aula. Nessa ocasião, Leonel e Murilo ficaram alheios, não participaram com os colegas de nenhuma brincadeira nos pequenos grupos que se formaram. $\mathrm{O}$ mesmo acontecia nos momentos de recreio, em que os alunos com NEEs por deficiência sempre se encontravam isolados ou reunidos entre eles, dificilmente com os colegas não deficientes, reflexo do que acontecia nos momentos formais de aula na escola.

Percebemos, nessas cenas, que os colegas mostram certa naturalização para o fato de Murilo e Leonel não participarem dos momentos de quadra/recreio. Podemos deduzir que os alunos podem 
ter assimilado o comportamento/atitude de professores/as que os segregam (Leonel e Murilo) e reproduzem esse comportamento/ atitude, deixando-os à margem, até porque nas aulas não há espaço/ tempo para uma reflexão crítica sobre o assunto com os alunos.

Essa situação nos chama a atenção para um problema grave na Educação/Educação Física: a escola, no processo de inclusão, pode estar formando os alunos para perpetuarem/reproduzirem atitudes de segregação de alunos com NEEs por deficiência, tornando natural a não participação deles nas atividades escolares e sociais, mantendo, por dentro do processo de inclusão, a exclusão. Ou seja, não contribuindo para transformar o quadro de segregação e discriminação existente antes do movimento de inclusão.

É injusto deixar crianças sem escola, sem lazer, sem comida, sem casa, sem saúde. Igualmente injusto é deixá-las na escola, matriculadas, sem acesso aos instrumentos e estratégias de que necessitam e sem professores que as respeitem e que se comprometam com seu processo educacional, sem profissionais na escola que deem apoio e orientação aos professores e familiares sem condições de infraestrutura e administrativas mínimas para o atendimento com qualidade.

A escola não pode se tornar um lugar igual aos outros lugares da vida das crianças, pelo contrário, deve ser responsável por uma vivência escolar mais rica e inovadora. Deve contribuir para que as crianças adquiram essa base mínima de conhecimentos culturais e científicos sem a qual ficam afastadas de uma presença efetiva na sociedade do conhecimento, e a Educação Física tem papel importante nesse processo.

Para Ferreira e Ferreira (2007) temos ainda hoje uma escola que não sabe bem como ensinar seus alunos 'tradicionais'. Para eles, vivemos um momento na educação em que coexiste a incapacidade da escola para ensinar todos os seus alunos e a presença de fato de alunos com deficiência, que são estranhos para ela. Tão estranhos 
que ela parece resistir em reconhecê-los como seus alunos, em desenvolver sua formação, em reconhecer um processo educativo relevante para eles.

Na Escola Azul, a inclusão se revelou para nós ora possível e palpável, ora utópica e distante, com possibilidades, mas também com limites. Porém, não podemos perder de vista que essa escola é parte do contexto maior de nossa sociedade. Ressaltamos a disponibilidade da maioria dos profissionais da escola em permitir nossa estada em seus ambientes. A aceitação da pesquisa na escola é, sem dúvida, um indicativo de que gostariam de dialogar conosco, de que gostariam de mudar a realidade de alguma forma.

No que diz respeito à disciplina curricular Educação Física, apesar do que os dados revelaram, acreditamos que ela pode, com rigor e com investimento, ser efectivamente uma área-chave para tornar a educação mais inclusiva e pode mesmo ser um campo privilegiado de experimentação, de inovação e de melhoria da qualidade pedagógica na escola. 
Physical education and inclusion: the experience at the "Blue" School

Abstract: It is a study case with ethnographic approaches, aiming at investigating and analyzing the process of inclusion of two students with special needs (NEEs) in the space-time of the Physical Education lessons. The instruments used were the field diary and the participant's observation. The empirical data point to a serious problem regarding Education/Physical Education: the school, in the process of inclusion, may be forming students to reproduce attitudes of segregation of the NEEs students by deficiency, making natural the nonparticipation of them in the school and social activities, keeping, within the process of inclusion, the exclusion. Keywords: Inclusion. School Physical Education. Everyday life.

Educación Física y la inclusión: la experiencia
en la Escuela Azul
Resumen: Estudio de caso con enfoques
etnográficos, con el objetivo de investigar y analizar
el proceso de inclusión de dos alumnos con
necesidades educativas especiales (NEEs) en el
espacio-tiempo de las clases de Educación Física.
Los instrumentos utilizados fueron el diario de campo
y la observación participante. Los datos empíricos
llámanos la atención para un grave problema en la
Educación/Educación Física: la escuela, en el proceso
de inclusión, puede estar formando los estudiantes
para reprodujeren actitudes de segregación de los
estudiantes con NEEs por discapacidades, haciendo
natural la no participación de estos en las actividades
escolares y sociales, manteniendo, en el interior del
proceso de inclusión, la exclusión.
Palabras clave: Inclusión. Educación Física.
Cotidiano.




\section{REFERÊNCIAS}

BARDIN, L. Análise de conteúdos. Lisboa: Edições 70, 1994.

BRACHT, Valter. Educação física e escola. Vitória, ES: Universidade Federal do Espírito Santo, Núcleo de Educação Aberta e a Distância, 2009.

CARVALHO, Rosita Edler. Removendo barreiras para a aprendizagem: educação inclusiva. 5. ed. Porto Alegre: Mediação, 2006.

CHICON, José Francisco. Inclusão na educação física escolar: construindo caminhos. 2005. 484 f. Tese (Doutorado) - Programa de Pós-Graduação em Educação, Faculdade de Educação, Universidade de São Paulo, São Paulo, 2005.

CHICON, José Francisco; DRAGO, Rogério; VICTOR, Sonia Lopes (Org.). A educação inclusiva de crianças, adolescentes, jovens e adultos: avanços e desafios. Vitória: EDUFES, 2010.

DAVIS, Cláudia; OLIVEIRA, Zilma de. Psicologia na educação. 14. ed. São Paulo: Cortez, 2003.

DUARTE, Newton. Educação escolar: teoria do cotidiano e a escola de Vigotski. 4. ed. Campinas: Autores Associados, 2007.

FERREIRA, Júlio Romero; FERREIRA, Maria Cecília Carareto. Sobre inclusão, políticas públicas e práticas pedagógicas. In: GOÉS, Maria Cecília Rafael de; LAPLANE, Adriana Lia Friszman (Org.). Políticas públicas de educação inclusiva. 2. ed. Campinas, SP: Autores Associados, 2007.

LEONTIEV, Alexis. Os princípios de desenvolvimento mental e o problema do atraso mental. In: LURIA, Alexander Romanovich; LEONTIEV, Alexis; VYGOTSKY, Lev Semenovich. Psicologia e pedagogia: bases psicológicas da aprendizagem e do desenvolvimento. São Paulo: Moraes, 1991. p. 59-76.

MITTLER, Peter. Educação inclusiva: contextos sociais. Porto Alegre: Artmed, 2003.

RESOLUÇÃO CNE/CEB nำ 2, de 11 de setembro de 2001. In: RIBEIRO, Maria Luisa Sprovieri; BAUMEL, Roseli Cecília Rocha de Carvalho (Org.). Educação especial: do querer ao fazer. São Paulo: Avercamp, 2003. p. 182-191. 


\section{ArtigosOriginais}

RODRIGUES, David. A educação física perante a educação inclusiva: reflexões conceptuais e metodológicas. In:CONGRESSO DE EDUCAÇÃO FÍSICA E DESPORTO DOS PAÍSES DE LÍNGUA PORTUGUESA, 7., 2000. Lisboa. Comunicação... Lisboa: FMH, 2000. Publicado no Boletim da Sociedade Portuguesa de Educação Física, 24/ 25, p. 73-81. 2005. Disponível em: <http://www.rc.unesp.br/ib/efisica/sobama/ sobamaorg/inicio.htm>. Acesso em: 20 fev. 2010.

VYGOTSKY, Lev. S. A formação social da mente. São Paulo: Martins Fontes, 1991. 
